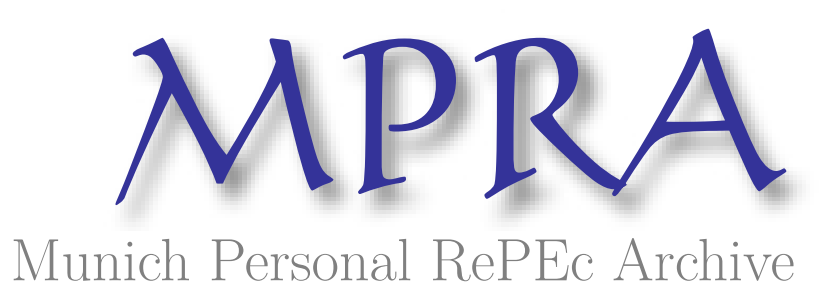

\title{
The Role of International Collaborations in Securing the Patent Grant
}

Drivas, Kyriakos and Kaplanis, Ioannis

, University of Piraeus, Athens University of Economics and Business, London School of Economics

April 2020

Online at https://mpra.ub.uni-muenchen.de/99520/

MPRA Paper No. 99520, posted 17 Apr 2020 10:55 UTC 


\title{
The Role of International Collaborations in Securing the Patent Grant
}

\author{
Kyriakos Drivas $^{1}$, Ioannis Kaplanis ${ }^{1,2,3}$ \\ ${ }^{1}$ Department of Economics, University of Piraeus, \\ Karaoli \& Dimitriou 80, Piraeus 18534, Greece \\ 2 Athens University of Economics and Business, \\ 76 Patission St., Athens 10434, Greece \\ ${ }^{3}$ SERC, London School of Economics, \\ Houghton Street, WC2A 2AE, London, UK
}

\begin{abstract}
Our study examines whether patent applications with international collaborations are more likely to be awarded a US patent than applications without. It contributes significantly to the growing literature that examines from the innovator's viewpoint the likelihood of securing the patent grant.The analysis focuses on the full sample (almost half a million) of patent applications over the period 2001-2009 at the USPTO, that disclosed at least one EU located inventor, and furthermore, explicitly distinguishes between countries with high and low number of patent applications. Firstly, we find that applications from teams rather than individual inventors are more successful in obtaining a patent grant, and that results are even better for international teams. Our key finding is that the presence of a US entity, either as inventor or owner, plays an important role in securing the grant. For low innovative countries, other types of international collaborations also matter significantly pointing to the benefits for these countries to become more extrovert. We further find that a large part of the US 'effect' can be attributed to additional prosecution efforts, as it is evident by continuing patent applications.
\end{abstract}

Keywords: International collaborations, likelihood of patent grant, USPTO, continuing patent applications, patent assignments.

JEL classification: $\mathrm{O} 31, \mathrm{O} 32, \mathrm{O} 34$

*The authors would like to thank participants from $54^{\text {th }}$ Colloquium ASRDLF $/ 15^{\text {th }}$ Conference ERSA-GR conference held in Athens (06-07-2017) and the $4^{\text {th }}$ Geography of Innovation Conference held in Barcelona (02-02-2018). All remaining errors are our own. 


\section{Introduction}

There has been an ever increasing interest, both academic- and policy-wise, on the process of obtaining a patent. There are strong reasons that place this process at the heart of innovation policy and therefore we are in need of better understanding on its mechanisms and implications.

First, organizations and inventors alike file more patent applications in recent years compared to the past, since they perceive this type of Intellectual Property as one of the main legal documents protecting and/or appropriating their inventions. In 1995 global patent applications marginally exceeded 1 million, while in 2015 this figure has risen to almost 2.9 million (source: WIPO). ${ }^{1}$

Second, patents have been shown to be related closely with a number of economy-wide variables. Since the study of Griliches (1981) scholars have shown that patents positively contribute to firm's market value (see for instance Tseng et al. 2005, Blundell et al. 1999, Sandner and Block 2011). Further, patents have been linked to the successful acquisition of venture capital by startups (Mann and Sager 2007), increased sales (Balasubramanian and Sivadasan 2011), increased exports (Chalioti et al. 2016) and potentially strengthen future M\&As (Breitzman et al. 2002). Moreover, the studies by Lerner (2009) and Moser (2005) provide some evidence that patents and patent laws may spur innovation.

The literature on the process of obtaining a patent, commonly referred to as patent prosecution, examines characteristics and behavior of the two parties involved: i) the patent office, representing the central planner, and ii) the innovators. While in the literature there has been significant progress in understanding the incentives and organization of the patent office, ${ }^{2}$ these is considerably less research work from the side of the innovators. In this paper, our focus is on the latter.

Our main objective is to examine whether international inventors' collaborations in a patent application are more likely to result in a patent than no such collaborations. In doing so, we also explicitly consider the owner's location and strategic activities to secure the patent grant. Our focus is on the $28 \mathrm{EU}$ member countries and we distinguish between countries with high and low innovative activity as evident by patent applications.

\footnotetext{
${ }^{1}$ These numbers were extracted from the WIPO Statistics Data Center: https://www3.wipo.int/ipstats/index.htm

${ }^{2}$ See for instance Frakes and Wasserman (2016), Lemley and Sampat (2012) and Schuett (2013).
} 
We draw information primarily from the PatEx dataset maintained by the Office of the Chief Economist at the USPTO. The PatEx dataset has detailed information for all patent applications that are published at the USPTO. We obtain information on virtually all patent applications filed between 2001 and 2009 that disclose at least one EU located inventor. We then provide several hypotheses that predict the likelihood of patent grant based on the existence and types of inventor collaborations.

When we examine the population of patent applications with EU located inventors, we find that applications stemming from teams, rather than individual inventors, are more likely to be issued a patent. This result is robust across all specifications and sample definitions. Next, we find that patent applications by international teams are more likely to be issued a patent.

Further, the overall presence of a US co-inventor or co-owner increases the likelihood of obtaining a grant; however, this result is heterogeneous between high and low innovative EU countries. These results however change qualitatively when we focus on patent applications that are less likely to be products of strategic or persistent patent prosecution; i.e. patent applications not associated with continuing patent applications. In particular, for such applications the presence of a US entity may still deliver a higher likelihood of patent grant; however, in most cases this effect diminishes pointing to the important role of strategic prosecution of obtaining a patent.

An important finding that emerges is that for less innovative countries, nonEU/non-US collaborations also deliver higher likelihood of patent grant. These overall findings indicate that for these countries international collaborations are beneficial in pursuing the right patentable inventions and further securing the patent grant pointing to the need for these countries to become more extrovert.

In a recent important study to the patent prosecution literature, Webster et al. (2014) examine the role of international collaborations in securing the patent grant. Our contributions to this study and the associated growing literature are the following: i) in addition to examining international inventor collaborations, we also examine the role of ownership, ii) we examine the role of strategic patent prosecution, as evident by the presence of continuing applications, in a joint framework with international collaborations.

A potential critique for this paper is that it focuses on US patent outcomes rather than EPO patent outcomes. Indeed, between the two big offices, EPO is the closest patent office for EU countries than the USPTO. While the EPO grants patents with 
higher standards (de Rassenfosse et al. 2016), the nature of the EPO system makes patent prosecution less appealing. Most importantly, for an EPO granted application to be active in all EU countries, the applicant needs to translate and validate to each country individually. The total cost can reach up to 30,000 Euros (Berger 2005; European Commission 2011), a cost so high which results in low validation rates for the majority of EU countries (Harhoff et al. 2009; Danguy and de la Potterie 2011). The above costs are one of the main reasons that have driven EU located entities to pursue patenting at the USPTO at higher rates than in the EPO. Indeed, according to both Offices' data ${ }^{3,4}$, during 2007-2014 EU countries filed for 518,649 EPO applications and 588,534 USPTO applications. ${ }^{5}$

The next section discusses the importance of patent prosecution for innovation and frames the hypotheses. Next, we describe the econometric strategy followed by the data construction section and discussion of summary statistics. The results section discusses the findings and finally the paper concludes.

\section{Related Literature and Hypothesis Framing}

\subsection{Importance of Patent Prosecution}

Many Northern EU countries experience a high GDP per capita and low unemployment rates while most of the EU South faces a number of challenges (Ezcurra and Pascual 2008). Further, and perhaps more importantly, convergence between these regions is still elusive and faced with many challenges (Kaitila 2004; Geppert and Stephan 2008). Both policy makers and scholars have identified that innovation activity is the engine of growth and a key in achieving a larger degree of economic coherence across countries (Jones 2005). Patents play an important role in this process as ideally they can provide incentives to innovate (Scothmer 2004). ${ }^{6}$

However, the innovator faces an uphill battle when it comes to granting her patent. In fact, only two in every three applications are issued a patent (see relevant data in Section 4).

\footnotetext{
${ }^{3}$ https://www.epo.org/about-us/annual-reports-statistics/statistics.html

${ }^{4}$ https://www.uspto.gov/web/offices/ac/ido/oeip/taf/appl_yr.htm

5 The high costs of patent prosecution for an EPO patent to be validated across all EU countries is one of the main reasons, EU will launch the Unitary Patent (see Economics 2014).

${ }^{6}$ There is a large debate on whether patents in their current form and institutional context can provide incentives to innovate or rather hinder innovation. While there are arguments or empirical observations in favor of the above statement (Lerner 2009, Moser 2005) and against (Bessen 2008, Heller and Eisenberg 2008, Murray and Stern 2008) this discussion is beyond the scope of the paper.
} 
However, for the innovator to devote time and money to a risky project, she needs to have an understanding on how to protect her invention. In countries where knowledge about the patent system is limited, the incentives to perform innovation activity are further diminished. To make matters worse, patent prosecution is costly and further associated with many hidden costs.

\subsection{Framing the Hypotheses}

Given the challenges and importance of securing the grant and clearing uncertainty of property rights, it is important to examine whether inventor composition plays a role. First and foremost, we should point to the need for teamwork. Singh and Fleming (2010) and Schettino et al. (2008) examine whether teams are associated with patents of higher quality. They find that teams deliver on average more important patents; further, breakthrough innovations are more likely to stem from teamwork. ${ }^{7}$ To the extent that higher quality inventions are associated with higher propensity of patent grant (Lei and Wright 2017), then the above findings could lead to the first testable Hypothesis $^{8}$ :

\section{Hypothesis 1: Teams should be associated with increased likelihood of patent grant}

Scholars have recently examined from the innovators' viewpoint the factors that can influence the likelihood of patent grant. In an early and most related, to ours, literatures, scholars have examined the likelihood of grant by inventor's origin country. ${ }^{9}$ Webster et al. (2014) examined whether, for a sample of approximately fifty thousand patent applications, patent grant outcomes in EPO and Japanese Patent Office (JPO) differ by inventor's home country. The authors found a strong positive home bias effect in both

\footnotetext{
${ }^{7}$ Agiakloglou et al. (2016) have shown that patents by team of inventors are also more likely to be commercialized.

${ }^{8}$ We do not follow a strict definition of Hypothesis statement. We merely aim to describe what are the predictions of this discussion for the likelihood of patent grant.

${ }^{9}$ A parallel literature to the following is the one that examines whether different patent offices across the world have different patentability standards. Webster et al. (2007) examined whether patent likelihood varied between EPO and JPO across a series of covariates. De Rassenfosse et al. (2016) examined patent grant outcomes in the five largest offices, including USPTO, with their main focus being on the standards of granting a patent. Sampat and Shandlen (2017) also examine secondary pharmaceutical patenting outcomes across patent offices. They find that procedural aspects play a key role in grant outcomes.
} 
offices. In other words, a patent application with Japanese inventor (European inventor) will be associated with a higher probability of patent grant in the JPO (EPO). ${ }^{10}$

In this paper, in addition to examining inventors we also consider applicants. In a patent application, there are two types of entities; the inventors and the owners. The inventors are persons that have invented the invention embedded in the patent application while the owner is the person, or legal entity, that owns the patent application. For instance, a patent application could disclose several inventors that are employed by a firm which is in turn is the application's owner.

The above study points to a testable hypothesis, tailor-made, for the USPTO:

Hypothesis 2: The presence of a US inventor or applicant, in the patent application, will increase the likelihood of grant

It is also important to consider the innovative capabilities of each country. Highly innovative countries, while may benefit from the above collaborations they are also likely to be knowledgeable of the patent system and have the resources to pursue a sound patent application. On the other hand, low innovative countries are less likely to have the knowledge or the resources. Therefore, they may indeed benefit more by the aforementioned collaborations. This leads to the fourth testable hypothesis:

Hypothesis 3: Patent applications from low innovative countries will benefit more, in terms of securing the patent grant, from all types of collaborations.

In a parallel literature, scholars have also examined whether different prosecution activities/strategies by patent applicants can increase the likelihood of patent grant. For instance, Henkel and Jell (2010) discuss the factors that may influence deferred examination in Germany while Yamauchi and Nagaoka (2015) studied this type of examination in Japan. Deferred patent examination takes place when the applicant requests from the patent office not to proceed to the review of the patent application for some time (usually months or few years). This action is not applicable to the US case as the USPTO does not allow for this action by applicants.

\footnotetext{
${ }^{10}$ In a recent study De Rassenfosse et al. (2017) examine standard-essential patent applications at the Chinese patent office and find that applications that are known to be essential to a standard by a foreign firm are likely to be treated unfavorably while similar patent applications by Chinese firms are not.
} 
Van Zeebroeck et al. (2009) show that patent applicants have increased the size of their patent applications making it harder and more time-consuming for examiners to review applications. This could be a strategy, at least for some applicants, to wear down the examiner and secure the grant (Lei and Wright 2017). De Rassenfosse et al. (2018) also show that the quality of the patent attorney hired by the applicant to draft the application and interact with the patent office increases the likelihood of the patent grant.

The above discussion shows that increased prosecution efforts by applicants can alter the outcome of patent grant. In the US, a major way for an applicant to increase the likelihood of patent grant is via the use of continuing applications. In the US, applicants have the option of filing patent applications claiming priority of a parent application; these latter applications are called continuing applications and are of three types: Continuations, Continuations-in-part and Divisionals. One of the main reasons, applicants opt for continuing applications is to secure patent grant of a variation of the original invention (for a more detailed discussion see Quillen and Webster 2001 and Quillen et al. 2002). Therefore, for this paper we should expect that the use of continuations will increase the likelihood of patent grant and further could dilute the role of co-inventorship or co-ownership:

Hypothesis 4: Continuing patent applications will be more likely to secure the grant. In addition, the may dilute the role of collaborations.

\section{Econometric Setup}

The above hypotheses point to the importance of the existence and types of collaborations for the likelihood of patent grant. In particular, to test Hypotheses 1 and 2 , the first series of regressions will be of the following form or similar versions thereof:

$$
\begin{aligned}
\text { Grant }_{i, u, c, y}= & a_{0}+a_{1} \text { Team }_{i, u, c, y}+a_{2} \text { International }_{i, u, c, y}+a_{3} \text { USCoinventor }_{i, u, c, y} \\
+ & a_{4} \text { USOWner }_{i, u, c, y}++a_{5} \text { InventorOwned }_{i, u, c, y}+a_{6} \text { PCT }_{i, u, c, y}+ \\
& u_{u}+c_{c}+y_{y}+\varepsilon_{i, u, c, y}
\end{aligned}
$$


Starting with the subscripts, $i$ denotes the $i^{\text {th }}$ patent application; $u$ denotes the first three-digit US patent classification that the $i^{\text {th }}$ patent application is assigned to; $c$ denotes the country, or countries, that the inventors of the $i^{\text {th }}$ patent application are located; $y$ is the application year of the $i^{\text {th }}$ patent application.

Team takes the value of 1 if the patent application has more than one inventor and 0 otherwise. International takes the value of 1 if the patent application has more than one inventor and at least two inventors are located in different countries and 0 otherwise.

USCoinventor takes the value of 1 if the patent application has at least one US located inventor and 0 otherwise. Similarly, USOwner takes the value of 1 if the patent application has a US located owner and 0 otherwise. We should highlight that a US owner is not uncommon; $15.3 \%$ of the patent applications in the sample, which have owner information, are owned by a US entity. Further, in the entire sample $8.7 \%$ of the patent applications disclose a US co-inventor. Finally, while there is significant overlap between the USCoinventor and USOwner dummies, there is still significant variation. $63.8 \%$ of the applications that disclose a US owner do not disclose a US co-inventor.

At this point, we should stress that via our data compilation process, we did not obtain owner information for $21 \%$ of the sample. We can reasonably assume that these are applications which are inventor owned. To control for this group of applications, we therefore include a dummy denoted as InventorOwned which takes the value of 1 if patent application lacks owner information and 0 otherwise. By including the USOwner and InventorOwned dummies, we compare the likelihood of grant between these applications and applications that are owned by a non-US entity. ${ }^{11}$

PCT takes the value of 1 if the patent application has followed the PCT route. Applicants that belong in countries that have ratified the Patent Cooperation Treaty (PCT) can file for a patent application at the World Intellectual Property Organization (WIPO). ${ }^{12}$ While WIPO does not have examination authority, the applicant can use WIPO to file to the jurisdictions she wishes via this latter office. This process gives the applicant more time to decide to which countries to protect her invention and therefore also delay paying application fees.

\footnotetext{
${ }^{11}$ As we include these two dummies, the comparable group is all other applications owned by a non-US firm or organization.

${ }^{12}$ Currently 152 countries have ratified the PCT.
} 
$u_{u}$ is a set of 463 dummies that capture the first three-digit US technology classification the patent application is assigned to. This technology classification is assigned by the USPTO once it receives the patent application ${ }^{13}$. For a more detailed discussion see Lerner (1994). $c_{c}$ is a set of 28 dummies that capture the location of the EU inventor(s). $y_{y}$ is a set of 9 dummies that capture the application year of the patent application.

Finally, we should note that for approximately $84 \%$ we have information on the number of claims filed. Therefore, for this subset of inventions we also add the number of claims (Claims) and the claims squared. The claims in a patent denote the scope of application the embedded invention can be used for. An applicant generally wishes to be issued a patent with many claims as this will provide her with broader monopoly rights (Kuhn and Thompson 2017); in that case such a patent application could be viewed with caution by the patent office. On the other hand a patent with many claims could be a, rather noisy, indication of a high quality patent (Bessen 2008). Therefore, how more claims in the application will affect the probability of grant remains an empirical question which we will examine in the following Section.

In the second set of models, we are further interested in the composition of the international collaborations. Therefore, for this part of the analysis we examine applications that disclose at least two inventors. More importantly, to test Hypothesis 3 , we will examine separately patent applications that disclose an inventor from a low innovative country and from a high innovative EU country. To this end, we classify EU countries in two groups. The first, TOP10EU, are the countries with the highest number of patent applications at the USPTO, and in our sample are associated with at least 10,000 patent applications each. ${ }^{14}$ These TOP10EU countries are AT, BE, DE, DK, FI, FR, UK, IT, NL and SE.

Inventors from these TOP10EU are likely to have access to more resources with respect to patent prosecution and more knowledge of the inner workings. The second, LOW18EU, are countries with lower patenting activity. These two groups of countries are distinctively different when it comes to patenting propensity as Hypothesis 3 hints. TOP10EU countries account for $95 \%$ of EU patenting, whereas LOW18EU for the rest.

\footnotetext{
${ }^{13}$ https://www.uspto.gov/web/patents/classification/uspcindex/indextouspc.htm

${ }^{14}$ For a time series see: https://www.uspto.gov/web/offices/ac/ido/oeip/taf/appl_yr.htm
} 
Starting with patent applications that disclose at least one inventor from a TOP10EU country, we estimate regressions of the following form:

$\operatorname{Grant}_{i, u, c, y}=\beta_{0}+\beta_{1}$ WithinTOP10EU $_{i, u, c, y}+\beta_{2}$ TOP10EU_LOWEU18 ${ }_{i, u, c, y}+$ $\beta_{3}$ USCoinventor $_{i, u, c, y}+\beta_{4}$ NonEUNonUSCoinventor $_{i, u, c, y}+a_{5}$ PCT $_{i, u, c, y}+u_{u}+$ $c_{c}+y_{y}+\varepsilon_{i, u, c, y}$

WithinTOP10EU takes the value of 1 if at least two inventors are from different countries and all inventors are located in TOP10EU countries and 0 otherwise. TOP10EU_LOW18EU takes the value of 1 if at least one inventor is from a LOW18EU country. NonEUNonUSCoinventor takes the value if at least one inventor is located outside the EU and US and 0 otherwise. The way the above regression is specified compares the WithinTOP1OEU, TOP1OEU_LOWI8EU, USCoinventor and NonEUNonUSCoinventor dummies with within same country collaborations from TOP10EU countries.

When we consider patent applications that disclose at least one inventor from a LOW18EU country, equation (2) changes slightly to:

$$
\begin{aligned}
& \text { Grant }_{i, u, c, y}=\beta_{0}+\beta_{1} \text { WithinLOW18EU }_{i, u, c, y}+\beta_{2} \text { TOP10EU_LOWEU18 } 8_{i, u, c, y}+ \\
& \beta_{3} \text { USCoinventor }_{i, u, c, y}+\beta_{4} \text { NonEUNonUSCoinventor }_{i, u, c, y}+a_{5} \text { PCT }_{i, u, c, y}+u_{u}+ \\
& c_{c}+y_{y}+\varepsilon_{i, u, c, y}
\end{aligned}
$$

In essence, we replace the WithinTOP1OEU with the WithinLOW18EU dummy which takes the value of 1 if at least two inventors are from different countries and all inventors are located in LOW18EU countries. Finally, in later regressions, we also include USOwner and InventorOwned dummies both to equations (2) and (3).

Finally, to test Hypothesis 4, we compare patent applications that are associated with continuing applications and the rest, denoted as stand-alone applications. We perform either separate estimations or include them together and examine any statistically significant different effect between the two groups in terms of team composition.

Note that we employ Ordinary Least Squares to estimate the above econometric model. While the dependent variable is a dummy and a probit or logit model could be 
used, the large number of fixed effects makes such estimators less precise (Angrist and Pischke, 2008). Several studies have opted for the linear probability model when they encompass a large number of fixed effects (see for instance Belenzon and Schankerman 2013). I any event, for our baseline estimations, we present results from probit estimations to provide robustness.

\section{Data Construction and Description}

\subsection{Data Construction}

Our primary source of data is the Office of the Chief Economist at the USPTO and in particular the PatEx database which describes in detail the prosecution history of all patent applications that opted for publication after November 20, 2000 (Graham et al. 2015). ${ }^{15,16}$ We extracted detailed information for 475,857 patent applications filed between 2001 and 2009 that disclose at least one inventor from one of the $28 \mathrm{EU}$ countries. Given that the dataset runs through 2015, our decision to stop at 2009 is to credibly identify patent applications that have been abandoned and have not been issued a patent and most likely will not be issued a patent in the future. ${ }^{17}$

A major contribution of this study is that we complement this dataset with information regarding the patent owner. This piece of information is important as we can examine whether the inventor collaboration findings are confounded by patent ownership. However, patent applications do not disclose the patent owner, as in the US only a person can file for a patent application. Therefore, only the inventors are disclosed at the patent application.

To extract information on patent ownership we rely again on the USPTO Office of the Chief Economist and the patent assignment dataset (Marco et al. 2015). ${ }^{18}$ In the US, once patents are transferred between entities, the transaction is disclosed at the USPTO. ${ }^{19}$ For the purpose of our study, we are interested on the first transaction of

\footnotetext{
${ }^{15} \mathrm{https}$ //www.uspto.gov/learning-and-resources/electronic-data-products/patent-examination-researchdataset-public-pair

${ }^{16}$ Before that date, patent applications in the US were not published. With the passage of AIPA, on November 20, 2000, patent applications that reserved the right to file abroad were published.

17 While certain patents may take more than six years to be granted, studies have shown that the overwhelming population is granted within few years from grant. For instance, Popp et al (2004) showed that $50 \%$ of patents takes at most 23 months to be granted. Further, Regibeau and Rockett (2010) found a similar average application length for a selected group of patents.

${ }^{18}$ https://www.uspto.gov/learning-and-resources/electronic-data-products/patent-assignment-dataset

${ }^{19}$ Disclosure as of yet is not mandatory. However, for legal reasons entities are inclined to disclose such transactions. For instance, in patent infringement cases the court needs to have clear view of patent ownership.
} 
each patent application that took place within a short period of time from application date. The usual practice is that once an application is filed, the inventor(s) if employed by a firm/organization, assign(s) ownership to her employer usually on the same day or within a few weeks/months. Therefore, by capturing the first transaction that has also occurred early we are able to capture the owner's country. We treat the firm/organization as applicant only if the assignment has taken place within 12 months from the date of application.

Via this methodology, we collected assignee's location information for 376,425 patent applications; approximately $79 \%$ of our sample. The rest could be patent applications that disclosed a patent owner but much later than twelve months. However, in all likelihood these are patent applications that did not have an owner and by default they were inventor-owned since they did not transfer ownership to a firm or organization..$^{20}$

\subsection{Data Description}

The average propensity of a patent application to be granted a patent is $65.4 \%$. This number however masks significant variation across countries and types of collaboration. Table 1 displays the average propensity of a patent application to be issued a patent by country and further distinguishes by type of collaboration: single inventor patent applications, teams where all the inventors are from the same country, and teams where at least one inventor is from a different country. ${ }^{21}$

As can be seen there is considerable variation across countries both for the overall patent grant likelihood and when accounting for the composition of the research team. The higher overall likelihood of patent grant belongs to low innovative countries such as Latvia, Romania and Lithuania but so does the lowest for countries such as Cyprus, Malta and Portugal. However, with such small number of patent applications we cannot safely draw any conclusions.

Turning our attention to the comparison between inventor collaborations, we observe that for half of the countries, either solely domestic or international teams deliver higher probability of patent grant than single inventors' patent applications.

\footnotetext{
${ }^{20}$ Data from other sources show similar percentages to USPTO. Agiakloglou et al. (2015) have found that approximately $15 \%$ of US patents issued between 1990-2000 belong to inventors. According to USPTO data, in 2015, $13 \%$ of patents belonged to inventors.

${ }^{21}$ We should note that the sum of observations exceeds the number of patent applications described early. This occurs because we double count patent applications that have inventors from multiple countries.
} 
Further, in thirteen out of twenty eight countries, international collaborations deliver higher probability of patent grant than domestic collaborations.

Looking into intra- and inter-EU collaborations, we further compare applications with TOP10EU- and LOW18EU-located inventors. Table 2 shows the likelihood of patent grant by type of collaboration. Column 1 includes all patent applications. Column 2 includes patent applications that have not generated continuing applications and they themselves are not continuing applications as well; i.e. the standalone applications. This group of patent applications can provide us with valuable insights as they are less likely to be associated with strategic (or increased) prosecution. In other words, in case the average patent application differs in the probability of patent grant than a stand-alone application, we can infer that at least a part of this difference is attributed to increased efforts by the applicant to obtain a patent. Indeed in all cases stand-alone applications have lower likelihood to be issued a patent than the average patent.

The highest probabilities of patent grant are observed for collaborations with US inventors and collaborations with TOP10EU countries. It is interesting to point that TOP10EU countries deliver high probability of patent grant both when inventors are from a single country and when inventors are from more than one TOP10EU country. Further, inventor collaborations with the US are associated with the highest propensity of patent grant.

Turning our attention to LOW18EU countries, they are overall associated with lower likelihood of obtaining a patent regardless of type of collaboration than TOP10EU countries. Further, collaborations with a US located inventor deliver the highest probability of patent grant than all other types of collaboration.

\section{Results}

Table 3 estimates versions of equation (1). Columns 1-4 consider all patent applications. In Column 1 only the coefficients of Team and PCT are included (in addition to the fixed effects). Starting with $P C T$, its coefficient is negative; a patent application with a PCT priority is $4.2 \%$ less likely to be issued a patent. The negative coefficient with respect to PCT is robust across all Columns. This result, at first glance may seem counterintuitive; applicants that first file to WIPO have more time to draft the patent application and in general have more time to plan their patent prosecution strategy. On the other hand, patent applications that are filed directly to the USPTO 
could be applications that the applicants consider valuable and of high quality and therefore do not want to waste time by filing at an interim office. This result is also corroborated by Guellec and van Pottelsberghe (2000) for a sample of patent applications at the EPO.

The coefficient of Team is positive and statistically significant at the $1 \%$ level. While the magnitude of the coefficient varies across Columns, it is always significant at the $1 \%$ level indicative of the positive role of teams in securing the grant validating Hypothesis 1.

In Column 2, we include the International dummy. Patent applicants with international collaboration are $2.9 \%$ more likely to be issued a patent than applications without. This coefficient remains significant across all specifications of Table 3. Goertzel et al. (2017) and Alonso-Martínez (2018) argue that international collaborations can have positive effects in the quality of innovation outcomes. Our results here corroborate the above studies by showing that international collaborations increase the likelihood of patent grant.

In Column 3, we include the USCoinventor dummy. Patent applications with a US co-inventor are $2.3 \%$ more likely to be issued a patent than applications without. However, in Column 4 when we include the USOwner and InventorOwned dummies, we observe that the USCoinventor dummy reduces in magnitude. On the other hand the USOwner dummy is positive and statistically significant. This result implies that US ownership plays an important role in securing the grant validating in part Hypothesis 2 on the presence of a US entity in the patent application.

Further, the coefficient of InventorOwned is negative and significant indicating that patent applications owned by inventors are less likely to be issued a patent than applications owned by non-US firms or organizations.

While the above findings provide insights on the average propensity of patent grant, they do not inform us on whether certain types of collaborations are associated with increased tendency of strategic patent prosecution or to the very least increased efforts to obtain a patent. To examine this further, in Columns 5-8, we focus strictly on patent applications that are not continuing applications and they themselves did not generate continuing patent applications (i.e. stand-alone patent applications). In other words, we focus on patent applications which their owners did not use continuation features to obtain a patent. 
Results are by and large similar in significance as before with one important distinction. In Column 8, the USCoinventor dummy is not significant. This implies that in applications where no continuations are used, US inventor collaborations are equally likely to deliver patent grant as other types of collaborations. However, the presence of a US owner is still associated with a higher likelihood of patent grant.

To examine if the differences are statistically significant between stand-alone applications and applications associated with a continuing application, we include all applications in Column 9 and include the following variables: Cont that takes the value of 1 if application is associated with a continuing application and 0 otherwise and the interaction of Cont with all the focal variables (Team, International, USCoinventor, USOwner and InventorOwned). Results are intuitive. The coefficient of Cont is positive and significant indicating that these applications indeed are more likely to be issued a patent consistent with Hypothesis 4. More importantly, the interaction terms of Cont_x_USCoinventor and Cont_x_USOwner are positive and significant implying that applications with a US Owner or a US co-inventor are even more likely to be issued with the use of continuing applications consistent again with Hypothesis 4 .

In Table A of the Appendix we re-estimate Table 3 via a probit model. Results are by and large similar providing robustness on the choice of the estimator. In Table B of the Appendix, we re-estimate Table 3 by including the Claims and Claims ${ }^{2}$. The sample reduces to the observations where we have claims information. Most results are qualitatively similar. ${ }^{22}$ The coefficient of Claims is positive and significant across the board. However, Claims ${ }^{2}$ is negative indicating diminishing returns to the positive role of the number of claims in the likelihood of grant. There can be two possible reasons for this positive association. First, to the extent that more claims represent larger patent scope, such applications on average could be of higher quality and therefore more likely to be issued a patent. Second, more claims could potentially wear down the patent examiner and therefore more likely to allow the patent to be granted. While the patent may be granted with fewer claims, it will nevertheless be patented. ${ }^{23}$

Thus far, we have examined collaborations for all patent applications. In the next two tables, we decompose by the location of the inventors effectively examining

\footnotetext{
${ }^{22}$ The only difference is that the USCoinventor dummy in Column 8 is negative and significant. However, this does not alter qualitatively our interpretation as the positive role is still primarily driven the USOwner dummy.

${ }^{23}$ For an excellent discussion on USPTO's resources and the difference between the number of filed and issued claims see Frakes and Wasserman (2015).
} 
Hypothesis 3. In Table 4, we consider patent applications that disclose at least one inventor from a TOP10EU country - we denote these as TOP10EU applications. Column 1 includes all patents. As before the coefficient of PCT is negative and statistically significant; a result that remains robust across all specifications. The coefficient of Team is again positive and significant. This result remains robust even when we only consider stand-alone applications in Column 4.

To focus on the types of collaborations in Column 2 we exclude patent applications that were filed by a single inventor and decompose the types of international collaborations as in equation (2) excluding the USOwner and InventorOwned dummies. The coefficient of WithinTOP1OEU shows that patent applications with collaboration within the TOP10EU countries are $1.4 \%$ more likely to be issued a patent than patent applications from TOP10EU countries without such international collaboration. Also, collaborations with US inventors are associated with higher likelihood of obtaining a patent but collaboration with LOW18EU is associated with lower likelihood. The only type of collaboration that is not statistically significant is the one with non-EU/non-US inventors. In Column 3, we include the USOwner and InventorOwned dummies. Results are similar to Table 3: both the existence of a US owner and/or co-inventor increase the likelihood of a grant while inventor owned patent applications are less likely to obtain a grant.

In Columns 4-6 we only consider stand-alone patent applications; the order of the Columns is similar to those of 1-3. In Column 5 we observe that none of the inventor collaborations is positive and strongly statistically significant. In Column 6, the USOwner dummy is, as previously, positive and statistically significant. The coefficient of NonEUNonUSCoinventor turns significant but only at the $10 \%$ level. These results show that when no continuations are used all types of inventor collaborations are similarly likely to be issued a patent as within a TOP10EU country's collaboration. However, US presence in the form of an owner still delivers higher likelihood of patent grant. Results are corroborated when we include all applications and include the Cont dummy and all the relevant interaction terms.

In Table 5 we consider patent applications that disclose at least one inventor from a LOW18EU country - we denote these as LOW18EU patent applications. Column 1 considers all such patent applications. The coefficient of PCT is again negative and significant across all specifications. The coefficient of Team is again 
positive and significant both in Column 1 and Column 4 where in the latter we consider stand-alone patent applications.

Column 2 estimates equation (3) by excluding the USOwner and InventorOwned dummies. Collaborations with US and non-EU/non-US inventors are positively associated with the likelihood of grant. When we include the USOwner dummy in Column 3, the coefficient of USCoinventor remains similar in magnitude and significance.

We should further note that the coefficient of NonEUNonUSCoinventor is positive and statistically significant across the both specifications (Columns 2-3).

In Columns 4-6 we only consider stand-alone patent applications. In Columns 4-6 no type of collaboration is statistically significant except for the coefficient of NonEUNonUSCoinventor in one out of two cases. ${ }^{24}$ In Column 6, the presence of a US owner increases the probability of patent grant. Column 7 includes all applications and accounts for which applications are associated with continuations. As previously, the coefficient of Cont is positive and significant. Interestingly, there is no statistical difference between stand-alone applications and those associated with continuations for the cases where a US owner is involved while in the case a US co-inventor is involved the latter types of applications are significantly more likely to be issued a patent.

The above results show that inventor composition and the presence of a US owner coupled with increased patent prosecution efforts matter. However, in certain aspects, they matter differently for high and low innovative EU countries. The presence of a US owner appears to matter more in the case of highly innovative countries while US inventor collaborations matter more for the case of the low innovative countries. For low innovative countries non-EU/non-US inventor collaborations also appear to matter for the likelihood of patent grant. The above results partly validate Hypothesis 3 with the exception of the role of US ownership for highly innovative countries. In both cases however, consistent with Hypothesis 4, we observe that a large part of the effects can be attributed to increased efforts of patent prosecution evident by continuing patent applications.

\footnotetext{
${ }^{24}$ We pursued this issue further and included a Non-EU/Non-US owner dummy; any positive role by Non-EU/Non-US inventor collaborations is then accounted by the Non-EU/Non-US owner dummy both for LOW18EU and TOP10EU countries. This indicates that any positive role Non-EU/Non-US entities have on the likelihood of patent grant can be attributed to ownership rather than inventor collaboration.
} 


\section{Conclusion}

At the forefront of protecting innovations, is the ability of inventors to obtain a patent for their inventions. Our setting is all patent applications filed at the USPTO over the period 2001-2009 and explicitly focus on EU located inventors. Our first finding is that teams are strongly associated with higher probability of obtaining a patent; a result consistent with the literature on teams and invention quality. For the average patent application, international collaborations can also increase the likelihood of patent grant.

With respect to TOP10EU countries, we find that collaborations with the US are associated positively with patent grant. Further US ownership also plays a positive role in obtaining a patent. Partly this US effect can be due to strategic patent prosecution as evident by continuations. Nonetheless, US ownership is also significant for the case of stand-alone patent applications.

With respect to LOW18EU countries, inventor collaboration with the US increases the likelihood of patent grant. Even after we include the US owner variables, US coinventorship stills remains significant. However, when we only consider standalone patent application, the positive role of US co-inventors dissipates. Finally, LOW18EU countries are also benefited from collaborations with other non-EU/nonUS pointing to the need for these countries to pursue international collaborations to gain experience in pursuing patentable inventions and better patent prosecution.

With respect to policy our results point towards the importance of the intricacies of patent prosecution and the tools that applicants have in their disposal in obtaining a patent. Further, they indicate that while inventor collaborations are important and can be prolific in obtaining a patent, the location of the owner also matters and in some cases may overshadow the role of inventor collaborations. 


\section{References}

Agiakloglou, C., K. Drivas, and D. Karamanis. "Individual Inventors and Market Potentials: Evidence from US Patents." Science and Public Policy 43, no. 2(2016): 14756.

Alonso-Martínez, D. (2018). Social progress and international patent collaboration. Technological Forecasting and Social Change, 134, 169-177.

Angrist, J. D., \& Pischke, J. S. (2008). Mostly harmless econometrics: An empiricist's companion. Princeton university press.

Balasubramanian, N., and J. Sivadasan. "What Happens When Firms Patent? New Evidence from U.S. Economic Census Data." Review of Economics and Statistics 93, no. 1(2011): 126-146.

Berger R (2005): A Study on the Cost of Patenting, prepared on behalf of the European Patent Office.

Bessen, J. (2008). The value of US patents by owner and patent characteristics. Research Policy, 37(5), 932-945.

Bessen, J., and M.J. Meurer. 2008. Patent failure: How Judges, Bureaucrats, and Lawyers put Innovators at Risk: Princeton University Press.

Blundell, R., R. Griffith, and J. Van Reenen. "Market share, market value and innovation in a panel of British manufacturing firms." Review of Economic Studies 66, no. 3(1999): 529-554.

Breitzman, A., Thomas, P., \& Cheney, M. (2002). Technological powerhouse or diluted competence: techniques for assessing mergers via patent analysis. R\&D Management, 32(1), 1-10.

Chalioti, E., Drivas, K., Kalyvitis, S., \& Katsimi, M. (2016). Innovation, Patents and Trade: A Firm-level Analysis.

de Rassenfosse, G., Jaffe, A. B., \& Webster, E. (2016). Low-quality patents in the eye of the beholder: Evidence from multiple examiners (No. w22244). National Bureau of Economic Research.

de Rassenfosse, G., Raiteri, E., \& Bekkers, R. (2017). Discrimination in the patent system: evidence from standard-essential patents.

de Rassenfosse, G., Jensen, P. H., Julius, T. M., Palangkaraya, A., \& Webster, E. (2018). Getting Patents: Does the Quality of Patent Attorney Matter?. Alfons and Webster, Elizabeth M., Getting Patents: Does the Quality of Patent Attorney Matter.

Danguy, J., \& de la Potterie, B. V. P. (2011). Cost-benefit analysis of the community patent. Journal of Benefit-Cost Analysis, 2(2), 1-43. 
Economics, E. (2014). Economic Analysis of the Unitary Patent and Unified Patent Court.

European Commission (2011) "Impact assessment accompanying document to the proposal for a regulation of the European Parliament and the Council implementing enhanced cooperation in the area of the creation of Unitary Patent protection and proposal for a Council regulation implementing enhanced cooperation in the area of the creation of Unitary Patent protection with regard to the applicable translation arrangements"

Ezcurra, R., \& Pascual, P. (2008). Fiscal decentralization and regional disparities: evidence from several European Union countries. Environment and Planning A, 40(5), $1185-1201$.

Frakes, M. D., \& Wasserman, M. F. (2015). Does the US Patent and Trademark Office Grant Too Many Bad Patents: Evidence from a Quasi-Experiment. Stan. L. Rev., 67, 613.

Frakes, M. D., and M. F. Wasserman. "Is the Time Allocated to Review Patent Applications Inducing Examiners to Grant Invalid Patents?: Evidence from MicroLevel Application Data." Review of Economics and Statistics (2016).

Geppert, K., \& Stephan, A. (2008). Regional disparities in the European Union: Convergence and agglomeration. Papers in Regional Science, 87(2), 193-217.

Goertzel, B., Goertzel, T., \& Goertzel, Z. (2017). The global brain and the emerging economy of abundance: Mutualism, open collaboration, exchange networks and the automated commons. Technological Forecasting and Social Change, 114, 65-73.

Graham, Stuart J.H. and Marco, Alan C. and Miller, Richard, The USPTO Patent Examination Research Dataset: A Window on the Process of Patent Examination (November 30, 2015). Available at SSRN: https://ssrn.com/abstract=2702637

Griliches, Z. "Market value, R\&D, and patents." Economic Letters 7, no. 2(1981): 183187.

Guellec, D., and B. van Pottelsberghe. 2000. "Applications, grants and the value of patent." Economics Letters 69:109-114.

Harhoff, D., K. Hoisl, B. Reichl, and B. van Pottelsberghe. "Patent Validation at the Country Level - The Role of Fees and Translation costs." Research Policy 38(2009): 1423-1437.

Heller, M.A., and R.S. Eisenberg. 1998. "Can Patents Deter Innovation? The Anticommons in Biomedical Research." Science 280:698-701.

Henkel, J., \& Jell, F. (2010). Patent Pending-Why faster isn't always better. Available at SSRN 1738912. 
Jones, C.I. 2005. "The Shape of Production Functions and the Direction of Technical Change." Quarterly Journal of Economics 120:517-549.

Kaitila, V. (2004). Convergence of real GDP per capita in the EU15. How do the Accession Countries fit in? (No. 025).

Kuhn, J. M., \& Thompson, N. (2017). The Ways We've Been Measuring Patent Scope are Wrong: How to Measure and Draw Causal Inferences with Patent Scope.

Lei, Z., \& Wright, B. D. (2017). Why weak patents? Testing the examiner ignorance hypothesis. Journal of Public Economics, 148, 43-56.

Lemley, M. A., and B. Sampat. "Examiner characteristics and patent office outcomes." Review of Economics and Statistics 94, no. 3(2012): 817-827.

Lerner, J. 1994. "The Importance of Patent Scope: An Empirical-Analysis." Rand Journal of Economics 25(2):319-333.

Lerner, J. "The Empirical Impact of Intellectual Property Rights on Innovation: Puzzles and Clues." American Economic Review Papers and Proceedings 99, no. 2(2009): 343348.

Mann, R. J., \& Sager, T. W. (2007). Patents, venture capital, and software start-ups. Research Policy, 36(2), 193-208.

Marco, Alan C., Graham, Stuart J.H., Myers, Amanda F., D'Agostino, Paul A and Apple, Kirsten, The USPTO Patent Assignment Dataset: Descriptions and Analysis (July 27, 2015). Available at SSRN: http://ssrn.com/abstract=2636461

Moser, P. "How Do Patent Laws Influence Innovation? Evidence from NineteenthCentury World's Fairs." American Economic Review 95, no. 4(2005): 1214-1236.

Murray, F., and S. Stern. 2007. "Do Formal Intellectual Property Rights Hinder the Free Flow of Scientific Knowledge? An Empirical Test of the Anti-Commons Hypothesis." Journal of Economic Behavior \& Organization 63:648-687.

Popp, D., T. Juhl, and D.K.N. Johnson. 2004. "Time in Purgatory: Examining the Grant Lag for U.S. Patent Applications." Topics in Economic Analysis and Policy 4(1 (Article 29)):1-43.

Quillen, C. D., and O. H. Webster. "Continuing patent applications and performance of the US Patent Office." Federal Circuit Bar Journal 11, no. 1(2001): 1-21.

Quillen, C. D., O. H. Webster, and R. Eichmann. "Continuing Patent Applications and Performance of the US Patent and Trademark Office-Extended." Federal Circuit Bar Journal 12, no. 1(2002): 35-55.

Regibeau, P.and K. Rockett. 2010. "Innovation Cycles and Learning at the Patent Office: Does the Early Patent Get the Delay?" Journal of Industrial Economics 58(2):222-246. 
Sampat, B. N., \& Shadlen, K. C. (2017). Secondary pharmaceutical patenting: A global perspective. Research Policy, 46(3), 693-707.

Sandner, P. G., and J. Block. "The market value of R\&D, patents, and trademarks." Research Policy 40, no. 7(2011): 969-985.

Schettino, F., Sterlacchini, A., \& Venturini, F. (2013). Inventive productivity and patent quality: Evidence from Italian inventors. Journal of Policy Modeling, 35(6), 10431056.

Schuett, F. "Patent quality and incentives at the patent office." Rand Journal of Economics 44, no. 2(2013): 313-336.

Scotchmer, S. (2004). Innovation and incentives. MIT press.

Singh, J., and L. Fleming. "Lone Inventors as Sources of Breakthroughs: Myth or Reality?" Management Science 56, no. 1(2010): 41-56.

Tseng, C. Y., \& James Goo, Y. J. (2005). Intellectual capital and corporate value in an emerging economy: empirical study of Taiwanese manufacturers. R\&D Management, 35(2), 187-201.

Van Zeebroeck, N., de la Potterie, B. V. P., \& Guellec, D. (2009). Claiming more: the increased voluminosity of patent applications and its determinants. Research Policy, 38(6), 1006-1020.

Webster, E., P. H. Jensen, and A. Palangkaraya. "Patent examination outcomes and the national treatment principle." Rand Journal of Economics 45, no. 2(2014): 449-469.

Webster, E., Palangkaraya, A., \& Jensen, P. H. (2007). Characteristics of international patent application outcomes. Economics Letters, 95(3), 362-368.

Yamauchi, I., \& Nagaoka, S. (2015). An economic analysis of deferred examination system: Evidence from a policy reform in Japan. International Journal of Industrial Organization, 39, 19-28. 
Table 1. Patent grant propensity by country and composition of inventor team.

\begin{tabular}{|c|c|c|c|c|c|}
\hline \multirow[b]{2}{*}{ Country } & \multirow[b]{2}{*}{ Obs } & \multicolumn{4}{|c|}{ Probability of Patent Grant } \\
\hline & & Overall & Single Inventor & $\begin{array}{c}\text { Whole } \\
\text { Team } \\
\text { Within } \\
\text { Country }\end{array}$ & $\begin{array}{c}\text { Foreign } \\
\text { Collaboration }\end{array}$ \\
\hline $\mathrm{AT}$ & 12,030 & $68.9 \%$ & $71.2 \%$ & $68.8 \%$ & $67.1 \%$ \\
\hline $\mathrm{BE}$ & 15,627 & $63.1 \%$ & $63.0 \%$ & $61.5 \%$ & $64.4 \%$ \\
\hline BG & 492 & $71.1 \%$ & $71.9 \%$ & $62.9 \%$ & $76.4 \%$ \\
\hline CY & 110 & $54.5 \%$ & $34.5 \%$ & $62.5 \%$ & $61.5 \%$ \\
\hline $\mathrm{CZ}$ & 1,374 & $66.1 \%$ & $64.0 \%$ & $63.0 \%$ & $68.9 \%$ \\
\hline DE & 187,412 & $66.9 \%$ & $69.4 \%$ & $66.7 \%$ & $64.2 \%$ \\
\hline DK & 11,490 & $61.2 \%$ & $66.6 \%$ & $59.3 \%$ & $59.1 \%$ \\
\hline EE & 210 & $65.7 \%$ & $51.9 \%$ & $68.1 \%$ & $67.4 \%$ \\
\hline ES & 8,949 & $59.7 \%$ & $61.0 \%$ & $58.0 \%$ & $61.2 \%$ \\
\hline FI & 16,313 & $63.5 \%$ & $65.4 \%$ & $63.3 \%$ & $60.5 \%$ \\
\hline FR & 69,252 & $67.6 \%$ & $69.9 \%$ & $67.9 \%$ & $64.3 \%$ \\
\hline GB & 80,735 & $61.6 \%$ & $61.6 \%$ & $60.4 \%$ & $63.7 \%$ \\
\hline GR & 927 & $57.0 \%$ & $51.2 \%$ & $57.2 \%$ & $59.6 \%$ \\
\hline HR & 318 & $57.9 \%$ & $71.6 \%$ & $49.2 \%$ & $58.9 \%$ \\
\hline $\mathrm{HU}$ & 1,632 & $55.6 \%$ & $57.4 \%$ & $55.7 \%$ & $54.7 \%$ \\
\hline IE & 5,092 & $59.5 \%$ & $59.1 \%$ & $56.4 \%$ & $62.6 \%$ \\
\hline IT & 32,473 & $68.4 \%$ & $69.4 \%$ & $68.2 \%$ & $67.0 \%$ \\
\hline LT & 135 & $78.5 \%$ & $90.0 \%$ & $79.1 \%$ & $76.8 \%$ \\
\hline LU & 985 & $73.2 \%$ & $73.6 \%$ & $72.0 \%$ & $73.5 \%$ \\
\hline LV & 141 & $48.9 \%$ & $46.7 \%$ & $71.4 \%$ & $44.8 \%$ \\
\hline MT & 62 & $54.8 \%$ & $60.0 \%$ & $44.4 \%$ & $57.9 \%$ \\
\hline NL & 32,051 & $61.6 \%$ & $66.2 \%$ & $58.5 \%$ & $62.4 \%$ \\
\hline PL & 1,206 & $61.6 \%$ & $54.7 \%$ & $54.7 \%$ & $68.4 \%$ \\
\hline PT & 643 & $52.9 \%$ & $50.8 \%$ & $55.6 \%$ & $51.5 \%$ \\
\hline RO & 401 & $74.3 \%$ & $75.6 \%$ & $65.8 \%$ & $76.5 \%$ \\
\hline SE & 24,560 & $65.5 \%$ & $68.1 \%$ & $65.7 \%$ & $61.2 \%$ \\
\hline SI & 478 & $58.2 \%$ & $53.5 \%$ & $60.4 \%$ & $58.0 \%$ \\
\hline SK & 317 & $62.8 \%$ & $71.7 \%$ & $62.3 \%$ & $60.0 \%$ \\
\hline
\end{tabular}


Table 2. Average probability of patent grant by type of inventor collaborations.

\begin{tabular}{lcc} 
Type & $\begin{array}{c}\text { All Patent } \\
\text { applications }\end{array}$ & $\begin{array}{c}\text { Stand-alone patent } \\
\text { applications }\end{array}$ \\
\hline 1. All Inventors Within a LOW18EU Country & $58.1 \%$ & $56.8 \%$ \\
2. All Inventors Within a TOP10EU Country & $65.2 \%$ & $64.7 \%$ \\
3. All Inventors Within LOW18EU Countries & $63.7 \%$ & $58.9 \%$ \\
4. All Inventors Within TOP10EU Countries & $63.2 \%$ & $62.1 \%$ \\
5. LOW18EU-TOP10EU Collaborations & $61.2 \%$ & $60.9 \%$ \\
6. LOW18EU-US Collaborations & $65.4 \%$ & $61.3 \%$ \\
7. TOP10EU-US Collaborations & $66.3 \%$ & $64.0 \%$ \\
8. LOW18EU-NonUS Collaborations & $61.9 \%$ & $61.6 \%$ \\
9. TOP10EU-NonUS Collaborations & $62.6 \%$ & $61.8 \%$ \\
\hline
\end{tabular}


Table 3. The role of collaborations in the overall likelihood of patent grant.

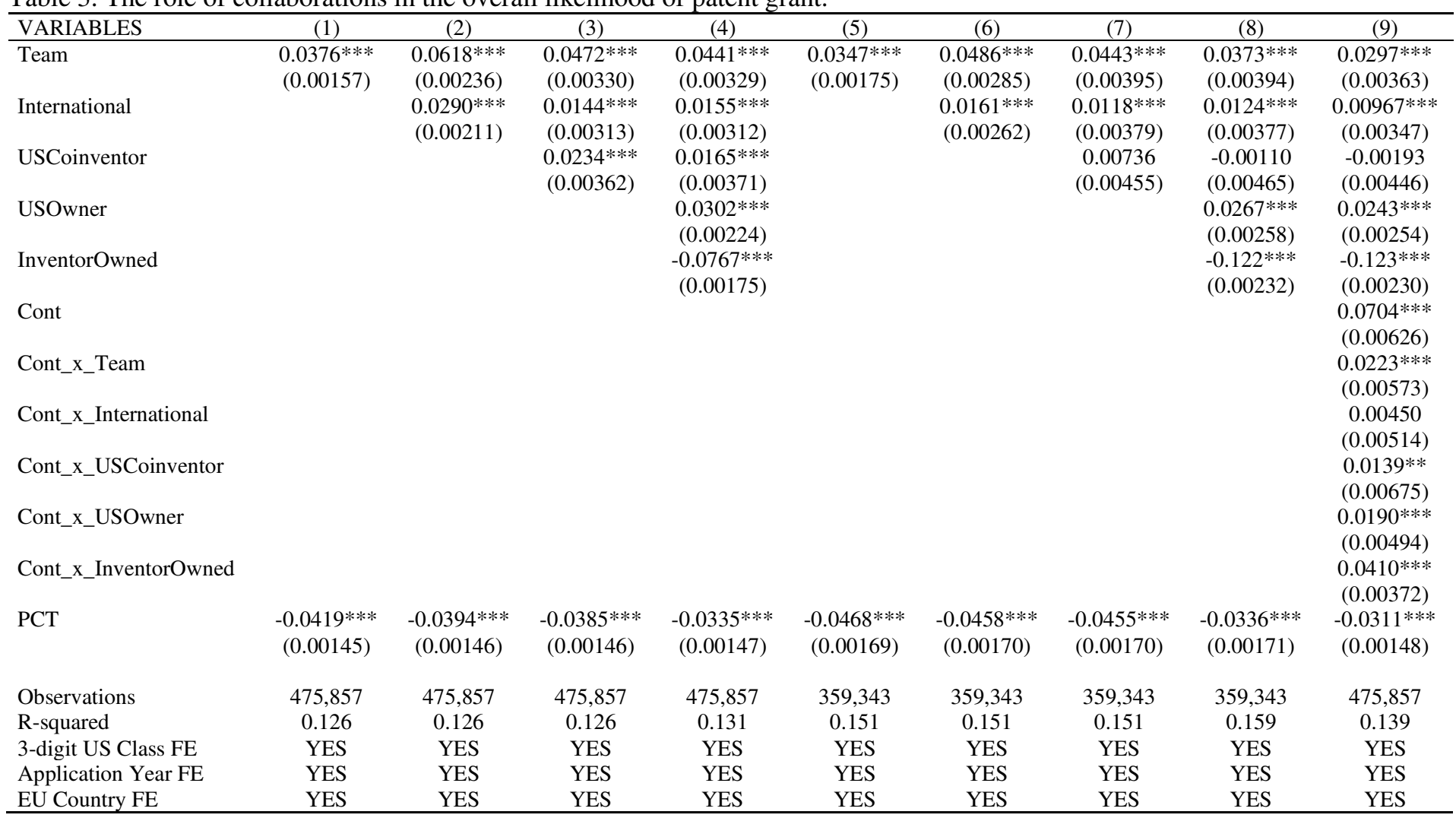

Notes: Dependent variable is a dummy that takes the value of 1 if patent application is granted and 0 otherwise. The estimation method is Ordinary Least Squares (OLS).

Columns 1-4 consider both stand-alone applications and applications related to continuing applications. Columns 5-8 consider only stand-alone applications. Column 9 includes all applications and includes a dummy Cont that takes the value of 1 if application is associated with a continuing application and 0 otherwise. It further includes interaction terms of Cont with the team composition variables. Standard errors are clustered at the first three-digit US patent classification. $* * * \mathrm{p}<0.01, * * \mathrm{p}<0.05, * \mathrm{p}<0.1$. 
Table 4. Probability of obtaining a patent. Decompose by type of international collaboration. Consider only applications with a TOP1OEU located inventor

\section{VARIABLES}

Team

WithinTOP10EU

TOP10EU_LOW18EU

USCoinventor

NonEUNonUSCoinventor

USOwner

InventorOwned

Cont

Cont_x_WithinTOP10EU

Cont_x_TOP10EU_LOW18EU

Cont_x_USCoinventor

Cont_x_NonEUNonUSCoinventor

Cont_x_USOwner

Cont_x_InventorOwned

PCT

\begin{tabular}{ccccccc}
$-0.0421 * * *$ & $-0.0422 * * *$ & $-0.0390 * * *$ & $-0.0468 * * *$ & $-0.0501 * * *$ & $-0.0403 * * *$ & $-0.0359 * * *$ \\
$(0.00147)$ & $(0.00173)$ & $(0.00174)$ & $(0.00169)$ & $(0.00203)$ & $(0.00204)$ & $(0.00174)$ \\
& & & & & & \\
457,471 & 334,608 & 334,608 & 359,343 & 245,287 & 245,287 & 334,608 \\
0.125 & 0.115 & 0.119 & 0.151 & 0.139 & 0.147 & 0.128 \\
YES & YES & YES & YES & YES & YES & YES \\
YES & YES & YES & YES & YES & YES & YES \\
YES & YES & YES & YES & YES & YES & YES \\
\hline
\end{tabular}

Observation

R-squared

3-digit US Class FE

Application Year FE

EU Country FE

(1)

$0.0366^{* * * *}$
$(0.00160)$

(2)

(3)

$0.0347 * * *$

$\begin{array}{cc}0.0141 * * * & 0.0113 * * \\ (0.00538) & (0.00537) \\ -0.113 * & -0.109 * \\ (0.0587) & (0.0587) \\ 0.0182 * * * & 0.0154 * * * \\ (0.00522) & (0.00529) \\ -0.000636 & 0.00399 \\ (0.00515) & (0.00513) \\ & 0.0266 * * * \\ & (0.00266) \\ & -0.0703 * * * \\ & (0.00217)\end{array}$

(0.00175)

(5)

0.00449
$(0.00688)$
-0.0562
$(0.0722)$
0.00827
$(0.00674)$
0.00718
$(0.00666)$

(7)

Notes: Dependent variable is a dummy that takes the value of 1 if patent application is granted and 0 otherwise. The estimation method is Ordinary Least Squ and applications related to continuing applications. Columns 4-6 consider only stand-alone applications. Column 7 includes all applications and includes a dummy Cont that takes the value of 1 if application is associated ** $p<0.05, * p<0.1$. 
Table 5. Probability of obtaining a patent. Decompose by type of international collaboration. Consider only applications with a $L O W 18 E U$ located inventor.

\begin{tabular}{|c|c|c|c|c|c|c|c|}
\hline VARIABLES & (1) & (2) & (3) & (4) & (5) & (6) & (7) \\
\hline Team & $\begin{array}{c}0.0593 * * * \\
(0.00839)\end{array}$ & & & $\begin{array}{c}0.0485^{* * *} \\
(0.00956)\end{array}$ & & & \\
\hline WithinLOW18EU & & $\begin{array}{l}8.41 \mathrm{e}-05 \\
(0.0170)\end{array}$ & $\begin{array}{c}-0.000327 \\
(0.0170)\end{array}$ & & $\begin{array}{c}0.0180 \\
(0.0219)\end{array}$ & $\begin{array}{c}0.0132 \\
(0.0218)\end{array}$ & $\begin{array}{c}0.0125 \\
(0.0211)\end{array}$ \\
\hline TOP10EU_LOW18EU & & $\begin{array}{c}0.0299 \\
(0.0222)\end{array}$ & $\begin{array}{c}0.0286 \\
(0.0222)\end{array}$ & & $\begin{array}{c}0.0297 \\
(0.0255)\end{array}$ & $\begin{array}{c}0.0221 \\
(0.0255)\end{array}$ & $\begin{array}{c}0.0267 \\
(0.0229)\end{array}$ \\
\hline USCoinventor & & $\begin{array}{c}0.0598 * * * \\
(0.0154)\end{array}$ & $\begin{array}{c}0.0572 * * * \\
(0.0157)\end{array}$ & & $\begin{array}{c}0.0289 \\
(0.0199)\end{array}$ & $\begin{array}{c}0.0218 \\
(0.0203)\end{array}$ & $\begin{array}{c}0.0148 \\
(0.0198)\end{array}$ \\
\hline NonEUNonUSCoinventor & & $\begin{array}{l}0.0289 * \\
(0.0156)\end{array}$ & $\begin{array}{c}0.0309 * * \\
(0.0157)\end{array}$ & & $\begin{array}{c}0.0311 \\
(0.0204)\end{array}$ & $\begin{array}{l}0.0358^{*} \\
(0.0203)\end{array}$ & $\begin{array}{l}0.0375^{*} \\
(0.0199)\end{array}$ \\
\hline USOwner & & & $\begin{array}{c}0.0120 \\
(0.0103)\end{array}$ & & & $\begin{array}{c}0.0246 * * \\
(0.0125)\end{array}$ & $\begin{array}{c}0.0171 \\
(0.0120)\end{array}$ \\
\hline InventorOwned & & & $\begin{array}{c}-0.0554 * * * \\
(0.00897)\end{array}$ & & & $\begin{array}{c}-0.0866^{* * * *} \\
(0.0118)\end{array}$ & $\begin{array}{c}-0.0840 * * * \\
(0.0116)\end{array}$ \\
\hline Cont & & & & & & & $\begin{array}{c}0.119 * * * \\
(0.0139)\end{array}$ \\
\hline Cont_x_WithinLOW18EU & & & & & & & $\begin{array}{c}-0.0585^{*} \\
(0.0337)\end{array}$ \\
\hline Cont_x_TOP10EU_LOW18EU & & & & & & & $\begin{array}{l}-0.0217 \\
(0.0196)\end{array}$ \\
\hline Cont_x_USCoinventor & & & & & & & $\begin{array}{c}0.0743 * * \\
(0.0309)\end{array}$ \\
\hline Cont_x_NonEUNonUSCoinventor & & & & & & & $\begin{array}{l}-0.0228 \\
(0.0313)\end{array}$ \\
\hline Cont_x_USOwner & & & & & & & $\begin{array}{c}0.0104 \\
(0.0213)\end{array}$ \\
\hline Cont_x_InventorOwned & & & & & & & $\begin{array}{c}0.0103 \\
(0.0183)\end{array}$ \\
\hline PCT & $\begin{array}{c}-0.0377 * * * \\
(0.00723)\end{array}$ & $\begin{array}{c}-0.0343 * * * \\
(0.00847)\end{array}$ & $\begin{array}{c}-0.0330 * * * \\
(0.00860)\end{array}$ & $\begin{array}{c}-0.0345 * * * \\
(0.00880)\end{array}$ & $\begin{array}{c}-0.0411 * * * \\
(0.0104)\end{array}$ & $\begin{array}{c}-0.0316^{* * * *} \\
(0.0106)\end{array}$ & $\begin{array}{c}-0.0292 * * * \\
(0.00861)\end{array}$ \\
\hline Observations & 23,214 & 18,276 & 18,276 & 16,452 & 12,497 & 12,497 & 18,276 \\
\hline R-squared & 0.154 & 0.150 & 0.152 & 0.187 & 0.184 & 0.189 & 0.164 \\
\hline 3-digit US Class FE & YES & YES & YES & YES & YES & YES & YES \\
\hline Application Year FE & YES & YES & YES & YES & YES & YES & YES \\
\hline EU Country FE & YES & YES & YES & YES & YES & YES & YES \\
\hline
\end{tabular}

Notes: Dependent variable is a dummy that takes the value of 1 if patent application is granted and 0 otherwise. The estimation method is Ordinary Least Squares (OLS). Columns 1-3 consider both stand-alone applications and applications related to continuing applications. Columns 4-6 consider only stand-alone applications. Column 7 includes all applications and includes a dummy Cont that takes the value of 1 if application is associated with a continuing application and 0 otherwise. It further includes interaction terms of Cont with the team composition variables. Standard errors are clustered at the first three-digit US patent classification. $* * *$ p $<0.01$, $* * \mathrm{p}<0.05, * \mathrm{p}<0.1$. 


\section{APPENDIX}

Table A. Re-estimate Table 3 via probit. Report Marginal Effects.

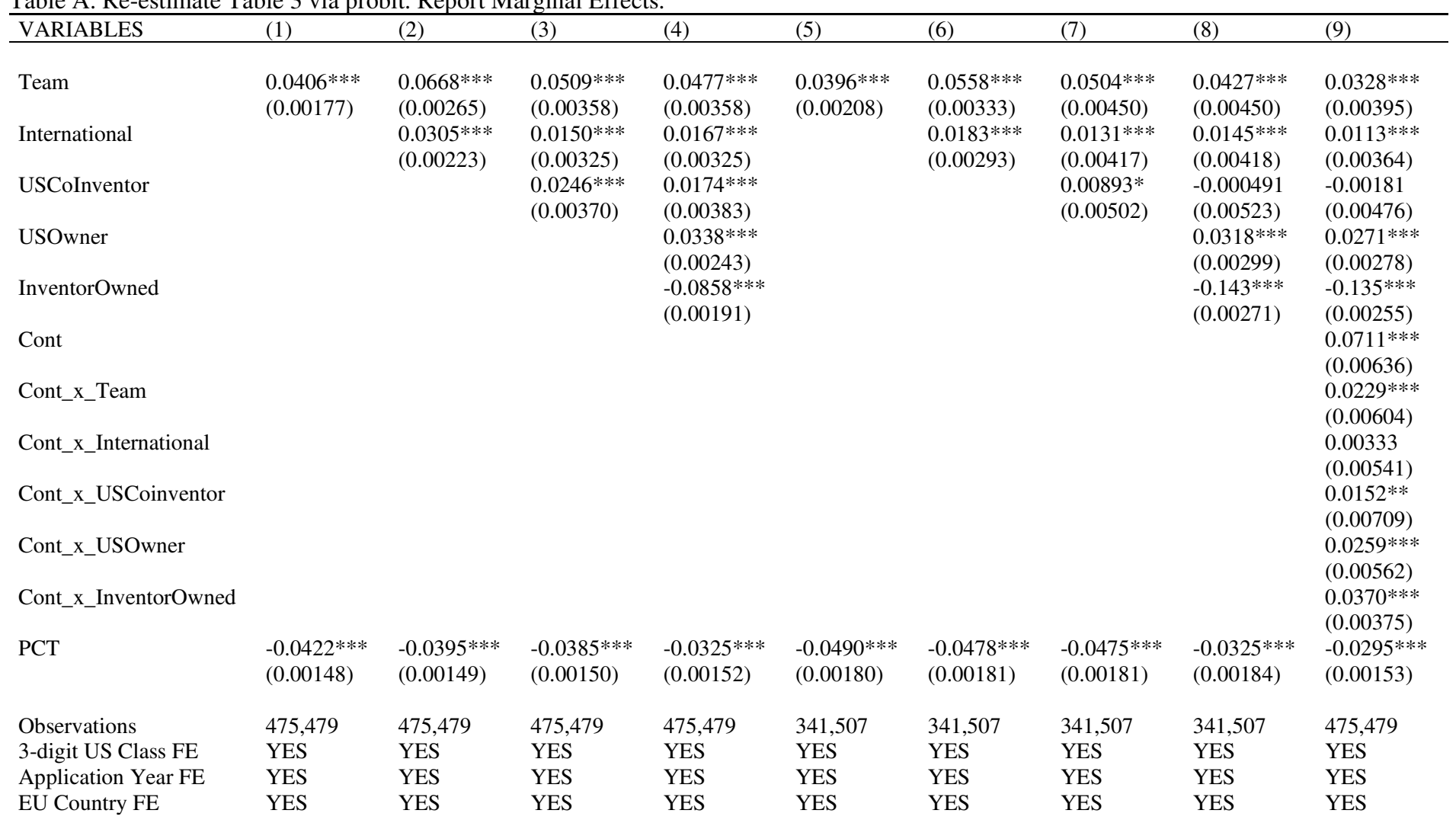

Notes: Dependent variable is a dummy that takes the value of 1 if patent application is granted and 0 otherwise. The estimation method is Probit. Columns 1-4 consider both stand-alone applications and applications related to continuing applications. Columns 5-8 consider only stand-alone applications. Column 9 includes all applications and includes a dummy Cont that takes the value of 1 if application is associated with a continuing application and 0 otherwise. It further includes interaction terms of $C o n t$ with the team composition variables. Standard errors are clustered at the first three-digit US patent classification. $* * * \mathrm{p}<0.01, * * \mathrm{p}<0.05, * \mathrm{p}<0.1$. 
Table B. Re-estimate Table 3 - Take into account Claims.

\begin{tabular}{|c|c|c|c|c|c|c|c|c|c|}
\hline VARIABLES & (1) & (2) & (3) & (4) & (5) & (6) & (7) & (8) & (9) \\
\hline Team & $\begin{array}{c}0.0398 * * * \\
(0.00177)\end{array}$ & $\begin{array}{c}0.0623 * * * \\
(0.00261)\end{array}$ & $\begin{array}{c}0.0497 * * * \\
(0.00358)\end{array}$ & $\begin{array}{c}0.0483 * * * \\
(0.00358)\end{array}$ & $\begin{array}{c}0.0361 * * * \\
(0.00200)\end{array}$ & $\begin{array}{c}0.0473 * * * \\
(0.00320)\end{array}$ & $\begin{array}{c}0.0470 * * * \\
(0.00434)\end{array}$ & $\begin{array}{c}0.0433 * * * \\
(0.00434)\end{array}$ & $\begin{array}{c}0.0373 * * * \\
(0.00399)\end{array}$ \\
\hline International & & $\begin{array}{c}0.0268 * * * \\
(0.00229)\end{array}$ & $\begin{array}{c}0.0142 * * * \\
(0.00335)\end{array}$ & $\begin{array}{c}0.0141 * * * \\
(0.00335)\end{array}$ & & $\begin{array}{c}0.0130 * * * \\
(0.00288)\end{array}$ & $\begin{array}{c}0.0126 * * * * \\
(0.00412)\end{array}$ & $\begin{array}{c}0.0127 * * * \\
(0.00412)\end{array}$ & $\begin{array}{c}0.00922 * * \\
(0.00376)\end{array}$ \\
\hline USCoinventor & & & $\begin{array}{c}0.0204 * * * \\
(0.00390)\end{array}$ & $\begin{array}{c}0.0103 * * * \\
(0.00400)\end{array}$ & & & $\begin{array}{l}0.000641 \\
(0.00499)\end{array}$ & $\begin{array}{c}-0.00940^{*} \\
(0.00512)\end{array}$ & $\begin{array}{c}-0.0106 * * \\
(0.00490)\end{array}$ \\
\hline USOwner & & & & $\begin{array}{c}0.0333 * * * \\
(0.00250)\end{array}$ & & & & $\begin{array}{l}0.0285 * * * \\
(0.00293)\end{array}$ & $\begin{array}{l}0.0253 * * * \\
(0.00287)\end{array}$ \\
\hline InventorOwned & & & & $\begin{array}{c}-0.0232 * * * \\
(0.00193)\end{array}$ & & & & $\begin{array}{c}-0.0584 * * * * \\
(0.00268)\end{array}$ & $\begin{array}{c}-0.0604 * * * * \\
(0.00267)\end{array}$ \\
\hline Cont & & & & & & & & & $\begin{array}{c}0.0936 * * * \\
(0.00668)\end{array}$ \\
\hline Cont_x_Team & & & & & & & & & $\begin{array}{c}0.00851 \\
(0.00612)\end{array}$ \\
\hline Cont_x_International & & & & & & & & & $\begin{array}{c}0.00246 \\
(0.00541)\end{array}$ \\
\hline Cont_x_USCoinventor & & & & & & & & & $\begin{array}{c}0.0230 * * * \\
(0.00719)\end{array}$ \\
\hline Cont_x_USOwner & & & & & & & & & $\begin{array}{c}0.0150 * * * \\
(0.00535)\end{array}$ \\
\hline Cont_x_InventorOwned & & & & & & & & & $\begin{array}{l}0.00684^{*} \\
(0.00408)\end{array}$ \\
\hline Claims (Coeff. Mult. By $10^{4}$ ) & $\begin{array}{c}6.763 * * * \\
(0.595)\end{array}$ & $\begin{array}{c}6.363 * * * \\
(0.582)\end{array}$ & $\begin{array}{c}6.235^{* * * *} \\
(0.579)\end{array}$ & $\begin{array}{c}5.835 * * * \\
(0.563)\end{array}$ & $\begin{array}{c}2.274 * * * \\
(0.540)\end{array}$ & $\begin{array}{c}2.113 * * * \\
(0.536)\end{array}$ & $\begin{array}{c}2.110 * * * \\
(0.537)\end{array}$ & $\begin{array}{c}1.872 * * * \\
(0.528)\end{array}$ & $\begin{array}{c}3.907 * * * \\
(0.478)\end{array}$ \\
\hline Claims $^{2}$ (Coeff. Mult. By $10^{4}$ ) & $\begin{array}{c}-0.000943 * * * \\
(0.000114)\end{array}$ & $\begin{array}{c}-0.000890 * * * \\
(0.000110)\end{array}$ & $\begin{array}{c}-0.000872 * * * \\
(0.000109)\end{array}$ & $\begin{array}{c}-0.000818^{* * * *} \\
(0.000105)\end{array}$ & $\begin{array}{c}-0.000300 \text { *** } \\
(8.04 \mathrm{e}-05)\end{array}$ & $\begin{array}{c}-0.000280 * * * \\
(7.94 \mathrm{e}-05)\end{array}$ & $\begin{array}{c}-0.000279 * * * \\
(7.94 \mathrm{e}-05)\end{array}$ & $\begin{array}{c}-0.000247 * * * \\
(7.76 \mathrm{e}-05)\end{array}$ & $\begin{array}{c}-0.000530 * * * \\
(8.01 \mathrm{e}-05)\end{array}$ \\
\hline PCT & $\begin{array}{c}-0.0397 * * * \\
(0.00154)\end{array}$ & $\begin{array}{c}-0.0375^{* * * *} \\
(0.00155)\end{array}$ & $\begin{array}{c}-0.0367 * * * \\
(0.00155)\end{array}$ & $\begin{array}{c}-0.0332 * * * \\
(0.00157)\end{array}$ & $\begin{array}{c}-0.0461 * * * \\
(0.00183)\end{array}$ & $\begin{array}{c}-0.0453^{* * *} \\
(0.00184)\end{array}$ & $\begin{array}{c}-0.0453^{* * *} \\
(0.00184)\end{array}$ & $\begin{array}{c}-0.0398 * * * \\
(0.00187)\end{array}$ & $\begin{array}{c}-0.0364 * * * \\
(0.00158)\end{array}$ \\
\hline Observations & 416,876 & 416,876 & 416,876 & 416,876 & 309,249 & 309,249 & 309,249 & 309,249 & 416,876 \\
\hline R-squared & 0.098 & 0.099 & 0.099 & 0.100 & 0.117 & 0.117 & 0.117 & 0.119 & 0.108 \\
\hline 3-digit US Class FE & YES & YES & YES & YES & YES & YES & YES & YES & YES \\
\hline Application Year FE & YES & YES & YES & YES & YES & YES & YES & YES & YES \\
\hline EU Country FE & YES & YES & YES & YES & YES & YES & YES & YES & YES \\
\hline
\end{tabular}

Notes: Dependent variable is a dummy that takes the value of 1 if patent application is granted and 0 otherwise. The coefficients of Claims and Claims ${ }^{2}$ are multiplied by $10^{4}$ for scaling. The estimation method is Ordinary Least Squares (OLS). Columns 1-4 consider both stand-alone applications and applications related to continuing applications. Columns 5-8 consider only stand-alone applications. Column 9 includes all applications and includes a dummy Cont that takes the value of 1 if application is associated with a continuing application and 0 otherwise. It further includes interaction terms of Cont with the team composition variables. Standard errors are clustered at the first three-digit US patent classification. $* * * \mathrm{p}<0.01, * * \mathrm{p}<0.05, * \mathrm{p}<0.1$. 